\title{
Panorama et futur de la filière du soja français
}

\author{
Françoise LABALETTE ${ }^{1}$ \\ Cécile BOURREL ${ }^{1}$ \\ Pierre JOUFFRET ${ }^{2}$ \\ Vincent LECOMTE ${ }^{2}$ \\ Alain QUINSAC ${ }^{3}$ \\ Stéphanie LEDOUX ${ }^{1}$ \\ 1 Onidol, \\ 12, avenue George V, \\ 75008 Paris, \\ France \\ $<$ f.labalette@onidol.fr> \\ 2 Cetiom, \\ 6, chemin de la Côte Vieille, \\ 31450 Baziège, \\ France \\ ${ }^{3}$ Cetiom \\ rue Monge, Parc industriel, \\ 33600 Pessac, \\ France
}

Confrontée à une baisse régulière des surfaces de soja en France depuis 2002 et alors même que les évolutions de l'agriculture et des marchés semblaient conférer un regain d'intérêt à la production nationale, l'interprofession des oléagineux, Onidol (Organisation nationale interprofessionnelle des oléagineux) et Cetiom (Centre technique interprofessionnel des oléagineux métropolitains), a lancé en 2007 un diagnostic de la filière du soja français. Cette étude, soutenue par l'Office national interprofessionnel des grandes cultures (ONIGC), dans le cadre du Plan d'accompagnement de la filière oléagineuse (Pafo), avait pour objectif de conduire un état des lieux depuis la production jusqu'à l'utilisation du soja français et d'en déduire quelques perspectives pour le futur. À cette occasion, des données accumulées sur le soja ont permis de compléter des analyses et de fournir des points de comparaison, notamment avec les résultats de l'enquête filière soja Cetiom-Onidol de 2002 (Labalette et Lecomte, 2003). Pour bénéficier d'un panorama actualisé de l'ensemble des maillons de la filière soja, des enquêtes ont été menées auprès de l'ensemble des opérateurs selon des techniques adaptées à chaque

\begin{abstract}
Soybean is cultivated in Europe as a GM free cultivation. In spite of a growing demand in identity preserved (IP) seeds and of the high environmental benefit of the soybean in the crop rotations, a great decrease of the soybean acreage has been observed in France and in Europe since 2002. That's why in 2007, Cetiom and Onidol, two bodies of the French oilseed crop organisation decided to carry out a comprehensive survey on the different actors of the soybean production chain from the farmers until the feed and food soybean users. The study showed that $12 \%$ of the total acreage is planted under organic farming and that most surfaces are still grown under IP process. It also highlighted that the decrease of soybean's surfaces till 2008 was mainly due to an insufficient economic competitiveness compared to other crops. The survey proved that the French production gained market shares between 2002 and 2007 for the soyfood industry supply (from 5 to 25\% of the total acreage). The remaining production is processed in small or medium extrusion plants for the local animal raising. The needs of the industry were described in details showing that the main asset of the French production is the good control of the whole production chain, the high quality management by the farmers, the good protein content and shorter logistic chains compared to the imported soybean. For the future, the increasing environmental constraints and the larger demand of European soyfood industry but also of local high-quality feed and animal raising could lead soybean to recover between 100000 and 150000 hectares in France.
\end{abstract}

Key words: soybean, French production, supply chain, economic chain secteur. La synthèse des résultats de cette étude permet de tracer quelques perspectives encourageantes pour l'avenir de la production française de soja.

\section{Premier oléagineux mondial}

Riche en protéines de bonne qualité (autour de $40 \%$ de la matière sèche) et contenant environ $20 \%$ d'huile, la graine de soja se consomme traditionnellement en alimentation humaine sous forme de soyfoods, terme qui regroupe diverses préparations à partir de graines entières (produits fermentés, jus de soja ou tonyu, tofu, etc.). En alimentation animale, I'utilisation se fait essentiellement sous forme de tourteaux déshuilés ou de graines traitées thermiquement. En effet, les graines crues renferment des facteurs antitrypsiques (FAT) qui diminuent notablement la digestibilité des protéines chez les animaux monogastriques et limitent leur incorporation dans les rations. Les FAT sont présents à des niveaux moyens compris entre 40 et $50 \mathrm{UTI} / \mathrm{mg}$ (unité trypsine inhibiteur) (AFZ et Cereopa, 2010), mais leur sensibilité à la chaleur fait que les process industriels peuvent facilement les éliminer des graines (toastage, extrusion) ou des tourteaux pendant leur désolvantation en usine de trituration.

Des procédés d'extraction et de concentration des protéines ont aussi été développés dans le monde pour conduire à des concentrats ou des isolats valorisés dans l'alimentation humaine ou animale.

Depuis les années 1980, les surfaces de soja dans le monde ont considérablement augmenté et placé cette culture au premier rang des oléagineux, avec plus de la moitié de la production planétaire de graines. Son développement a été tiré par la demande en tourteaux émanant des élevages, d'abord européens et nord-américains et, depuis une dizaine d'années, par des pays du bloc asiatique, Chine en tête. Par conséquent, si sa culture reste concentrée entres les mains de trois grands pays du continent américain, États-Unis, Brésil et Argentine (figure 1), la consommation des graines, des tourteaux et de l'huile de soja est davantage répartie à travers le monde, avec pour conséquence d'intenses échanges internationaux (30 à $35 \%$ des produits du soja sont échangés (Daydé, et al., 2009). L'Union européenne (UE) en est la 


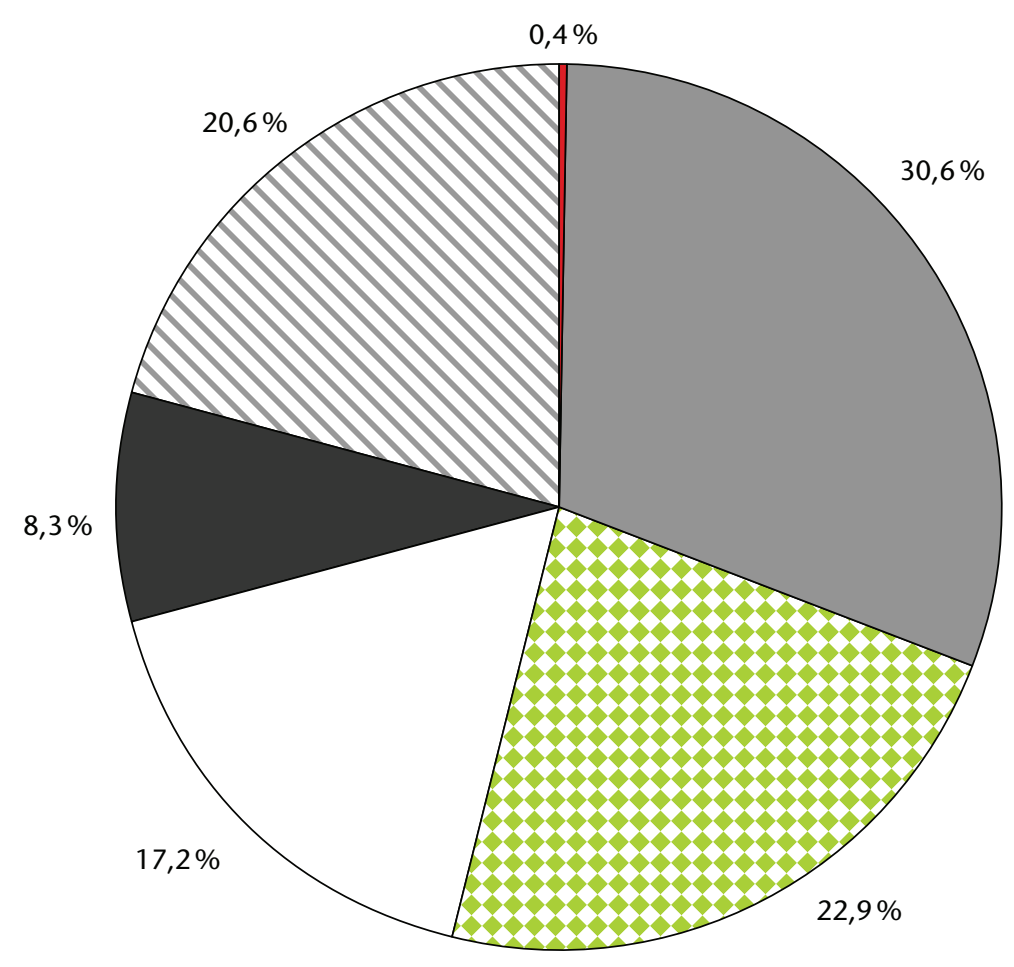

Total surfaces: 103 millions ha

Production: 259 millions tonnes de graines

\begin{tabular}{lll}
\hline$\square$ UE 27 & $\square$ USA & $\square$ Brésil \\
$\square$ Argentine & $\square$ Chine & $\square$ Autres
\end{tabular}

Figure 1. Principaux pays producteurs de soja dans le monde en 2010. Source : Oil world 2010.

parfaite illustration avec une production de soja particulièrement faible (885 000 tonnes en 2009) au regard de ses besoins en tourteaux de soja (31,9 millions de tonnes consommées en 2009) et, dans une moindre mesure, en huile de soja (2,6 millions de tonnes en 2009). Rien d'étonnant donc à ce que l'UE soit devenue très dépendante des importations de soja, que ce soit sous forme de graines (13,2 millions de tonnes en 2009) pour les pays dotés d'outils de trituration, ou sous forme de tourteaux (21,9 millions de tonnes en 2009) pour les autres. Depuis la fin des années 1990, l'extension continue des surfaces en culture de soja OGM (organisme génétique modifié) dans le monde, et en particulier aux États-Unis (93\% des surfaces selon un rapport de I'USDA) et en Argentine, a conduit à une segmentation du marché, notamment dans I'UE. Des filières d'approvisionnement de soja dites «OGMfree » ou « PCR négatif », ainsi que des filières identity preserved (IP) se sont mises en place, dans un premier temps à partir du Brésil, puis d'autres pays comme le Canada.

\section{En France, une grosse consommation de soja mais une production mise à mal depuis 2001}

La France, qui a développé peu d'outils de trituration dédiés au soja, n'échappe pas à la règle en important annuellement autour de 4 millions de tonnes de tourteaux de soja (3,7 millions de tonnes en 2009) pour guère plus de 0,5 million de tonnes de graines. Le principal fournisseur de tourteaux de soja reste de loin le Brésil (72\% des importations en 2009). Malgré un développement non négligeable d'autres sources protéiques comme le tourteau de colza, le tourteau de soja représente encore plus de la moitié des 7,5 millions de tonnes de tourteaux consommés en France et il demeure incontournable pour un certain nombre d'usages, dont l'alimentation des volailles en particulier (plus de $60 \%$ des débouchés chez les fabricants d'aliments). Là aussi, une segmentation s'est dessinée puisque certains cahiers des charges de la filière animale (le bio, certains labels ou appellations d'origine contrôlée, etc.) excluent le tourteau GM fabriqué à partir de soja génétiquement modifié.

Enfin, aux côtés de I'utilisation sous forme de tourteau de soja, d'autres valorisations de la graine ont émergé en France depuis les années 1990, d'abord basées sur le traitement thermomécanique (principalement extrusion) de la graine entière en vue de son incorporation en alimentation animale, puis, plus récemment, comme matière première de l'industrie des soyfoods.

Certes bien modeste en regard du gros contingent de soja importé des pays tiers, la production française, démarrée il y a plus de 30 ans sous l'impulsion de l'interprofession des oléagineux, a fourni selon les campagnes entre 100000 et 300000 tonnes de graines de soja (prévisionnel de 121000 tonnes pour 2010, selon FranceAgriMer, septembre 2010). Au niveau de I'UE, I'Italie est en tête des surfaces implantées et la France s'est depuis longtemps installée au second rang, place parfois disputée avec la Roumanie après l'élargissement de I'Union (figure 2).

Affichant une surface moyenne de 75000 ha sur les 20 dernières années, les surfaces françaises ont fortement fluctué au gré notamment des régimes de la Politique agricole commune (Pac). Depuis 2002, après deux années fastes, les superficies n'ont cessé de décroître jusqu'en 2008, comme d'ailleurs dans tous les pays traditionnellement producteurs de I'UE (figure 3).

\section{Rendements réguliers en France mais évoluant peu depuis 20 ans}

Les producteurs (enquête agriculteurs, Cetiom 2007) considèrent le soja comme une culture au rendement globalement régulier et sans surprise. Cette perception est confirmée par les rendements moyens français qui montrent une bonne stabilité, hormis les années à événement climatique exceptionnel : pluies excessives de l'automne 1992 et sécheresse extrême de 2003 (figure 4)

La progression des rendements est, en revanche, faible et deux freins techniques ont été clairement identifiés pendant cette étude :

- le désherbage: les producteurs estiment que $50 \%$ de leurs parcelles sont mal ou moyennement désherbées. Ce point est à mettre en relation avec le faible pouvoir concurrentiel du soja en début de cycle et une gamme de solutions chimiques, de coût modéré, qui s'est appauvrie au cours des dernières années (retraits de : trifluraline, linuron, etc.) limitant les possibilités de désherbage efficace à coût raisonnable ; 


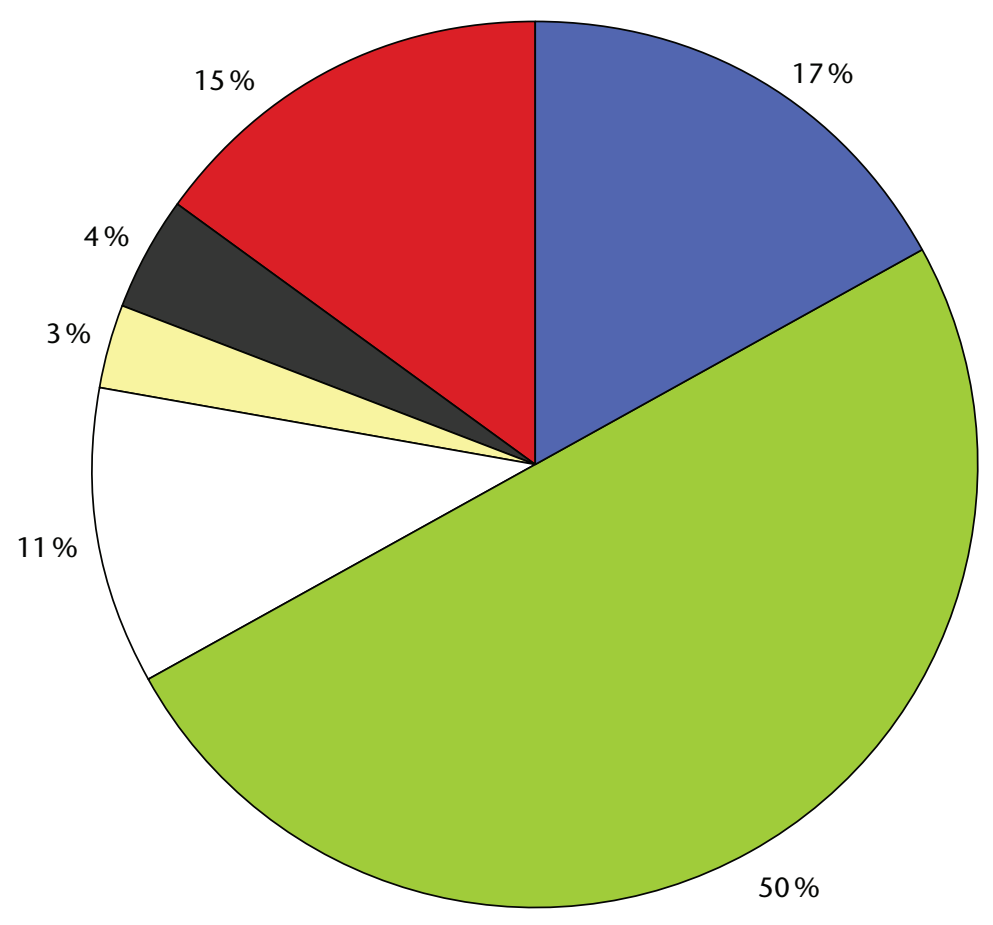

Total surfaces: 304000 ha

Production totale graines: 853000 tonnes

\begin{tabular}{|lll|}
\hline$\square$ France & $\square$ Italie & $\square$ Autriche \\
$\square$ R. Tchèque & $\square$ Slovaquie & $\square$ Roumanie \\
\hline
\end{tabular}

Figure 2. Surfaces de soja dans I'UE en 2010 (données provisoires). Sources : Oil world 2010 et CopaCogeca 2010.

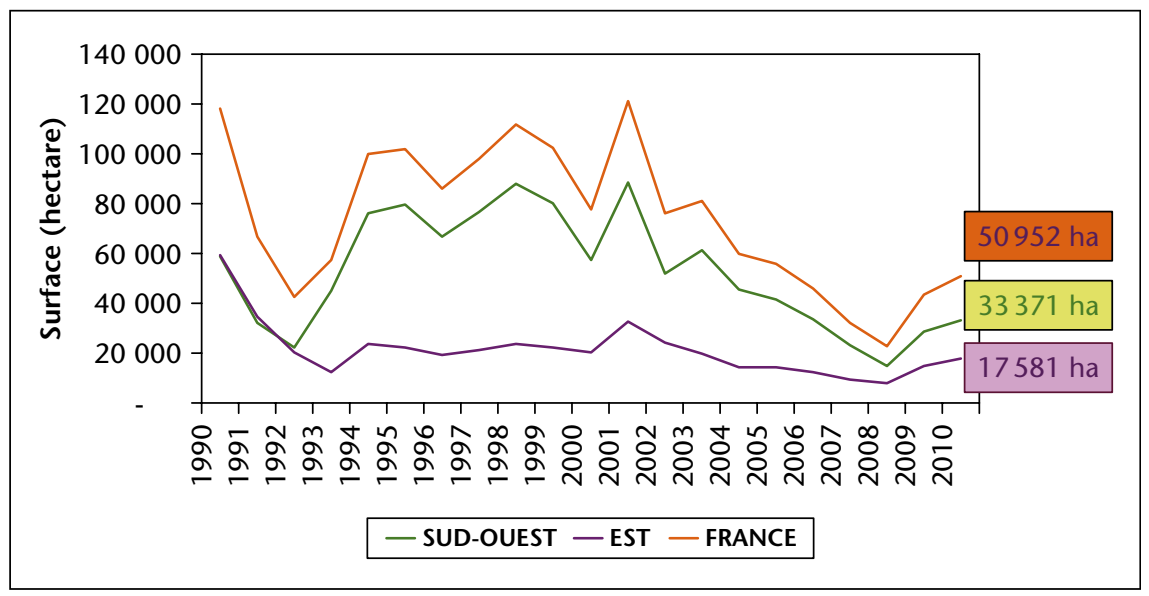

Figure 3. Évolution des surfaces de soja en France, Agreste, octobre 2010.

- l'irrigation: les enquêtes montrent clairement que les producteurs n'irriguent pas à l'optimum économique leurs productions et que, en moyenne, un à deux tours d'eau complémentaires seraient bien valorisés.

La nodulation, qui permet la nutrition azotée du soja sans apport d'engrais azoté grâce à une symbiose bactéries plantes s'effectuant dans des nodosités situées sur les racines, est considérée comme satisfaisante. La qualité d'inoculation du sol en bactéries) commercialisés est donc reconnue de bon niveau, ce qui n'a pas toujours été le cas dans le passé. des inoculums (nécessaires à l'opération
Les dégâts de ravageurs, malgré l'arrivée depuis 2007 de la pyrale des haricots et la présence plus ou moins forte chaque année $d^{\prime}$ acariens et de punaises vertes, $n^{\prime}$ apparaissent pas à ce jour comme un réel problème.

Quant aux variétés, vecteur de progrès potentiel de la culture, leur bilan apparaît contrasté. Le renouvellement de l'offre variétale française est assez lent au cours de ces dernières années : par exemple, une seule variété a été inscrite au catalogue français en 2010 en soja contre 15 pour le tournesol. Néanmoins, les variétés mises sur le marché depuis une dizaine d'années ont permis de répondre globalement aux besoins des utilisateurs tant en termes de précocité adaptée aux différentes régions et modes de production (classique ou dérobé) que de qualité (teneur en protéines). La productivité des variétés a globalement progressé, mais on peut se demander si l'accent mis sur la teneur en protéines pour répondre efficacement aux besoins du marché, alimentaire en particulier, $n^{\prime}$ en a pas ralenti momentanément I'amélioration globale (tableau 1). Les variétés actuelles présentent aussi très généralement une bonne tenue à la verse, ce qui n'était pas vrai il y a une vingtaine d'années, tandis que le bilan concernant la tolérance au Sclérotinia est moins favorable (plusieurs variétés du marché sont sensibles ou assez sensibles à cette maladie).

On notera, enfin, que les producteurs français utilisent de façon importante les semences de ferme (69\% des surfaces dans le Sud-Ouest, $37 \%$ dans l'Est selon l'enquête Cetiom 2007). À court terme, leur motivation est essentiellement économique (recherche d'une baisse des charges), mais ce choix n'est pas sans risque dans la mesure où seules les semences certifiées permettent de garantir l'identité variétale ainsi que la qualité sanitaire des semences. De surcroît, le manque à gagner qui en résulte pour les sociétés de semences est un frein majeur au développement de la recherche, à même de générer les progrès génétiques indispensables à la compétitivité de la culture en France et en Europe.

\section{Bénéfices environnementaux indéniables dans les systèmes de culture français}

L'introduction du soja dans les assolements de grandes cultures présente trois types d'avantages vis-à-vis de l'environnement. En premier lieu, l'absence d'apport d'azote sur soja et, dans les rotations avec le maïs, l'économie de 30 à $50 \mathrm{~kg}$ d'azote par hectare sur le maïs qui suit permettent une réduction substantielle de l'application d'engrais azotés dans l'assolement (tableau 2) (Lacroix et al., 1998) avec, 


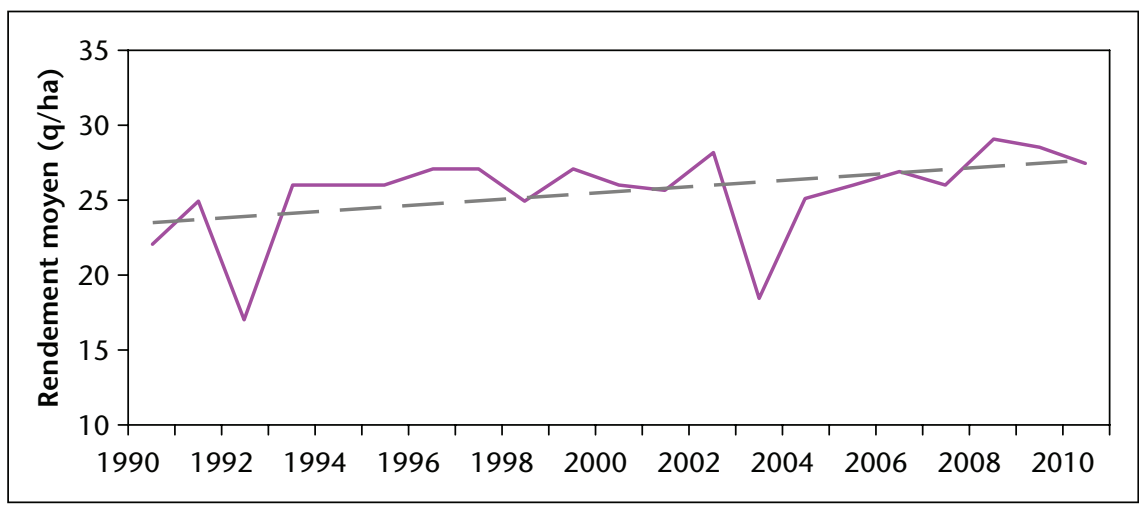

Figure 4. Évolution des rendements en graines soja en France, Agreste, novembre 2010.

Tableau 1. Évolution de la teneur en protéines des variétés de soja cultivées en France (enquêtes postales Cetiom correspondant à 467 parcelles en 2003 et à 300 parcelles en 2007).

\begin{tabular}{|lcc|}
\hline Teneur en protéines & \multicolumn{3}{l|}{ Taux de parcelles $\mathbf{( \% )}$} \\
\cline { 2 - 3 } des variétés & $\mathbf{2 0 0 3}$ & $\mathbf{2 0 0 7}$ \\
\hline Élevée & 8 & 29 \\
\hline Moyenne & 61 & 58 \\
\hline Faible & 31 & 13 \\
\hline
\end{tabular}

Tableau 2. Comparaison des quantités annuelles d'azote à apporter dans une rotation soja/maïs par rapport à une monoculture de maïs (maï/maiis). Essais Cetiom, AGPM (1994-1997).

\begin{tabular}{|lll|}
\hline Rotation & Maïs/soja & Maïs/maïs \\
\hline $\begin{array}{l}\text { Apport moyen } \\
\text { d'azote minéral N en }\end{array}$ & & 210 \\
kg/ha par an & & \\
\hline
\end{tabular}

parallèlement, une légère réduction de risque de pertes de nitrates dans les eaux (Reau et al., 1998).

En second lieu, dans les secteurs irrigués à dominante maïs, l'introduction du soja se traduit par une diminution des quantités d'eau utilisées puisque les apports d'eau sur soja sont en moyenne inférieurs de l'ordre de $500 \mathrm{~m}^{3} /$ ha à ceux apportés au maïs. Elle permet aussi une meilleure répartition des prélèvements durant l'été. Enfin, l'utilisation limitée de produits phytosanitaires liée à la quasi-absence de traitements contre les ravageurs ou les maladies (les seules interventions concernant la maîtrise du désherbage) et la diversification apportée par la présence du soja dans la rotation (rupture du cycle des maladies dans les céréales, etc.) permettent de contribuer à une diminution substantielle de l'utilisation de produits phytosanitaires à l'échelle de la rotation (Labalette et al., 2008).
Ces avantages agronomiques font aussi du soja une culture de choix dans les systèmes de cultures biologiques (bio). Bien adapté au désherbage mécanique (faux semis, herse-étrille, binage, etc.), capable de s'alimenter naturellement en azote sans apport d'engrais azoté et peu sujet aux maladies et attaques de ravageurs, le soja peut atteindre, dès lors qu'il est correctement conduit, des rendements proches de ceux atteints en agriculture conventionnelle. Le soja apparaît ainsi comme une culture incontournable dans les assolements bio du Sud comme de l'Est de la France. En effet, dans l'enquête 2007, le soja bio représente entre $12 \%$ (Sud-Ouest) et $14 \%$ (Est) des surfaces de soja totales, soit près de 4000 ha, proportion à comparer aux 2,12\% de bio pour l'ensemble des cultures arables en 2008. II demande, cependant, un savoir-faire particulier pour le désherbage : les techniques de préparation du sol et de désherbage mécanique devront être pratiquées avec grande attention pour garantir une maîtrise satisfaisante des adventices.

\section{Rentabilité érodée suite à Agenda 2000}

Deux facteurs majeurs ont un impact sur la rentabilité du soja, celle-ci influant directement sur les surfaces en cette culture au niveau français. Le premier est de nature réglementaire avec un fort effet sur la sole de soja des évolutions successives de la Pac et des éventuelles mesures d'aide spécifique au soja. Le second facteur majeur est économique avec une influence marquée des écarts de marges brutes observés entre le soja et les principales cultures concurrentes dans l'assolement que sont le maïs irrigué dans les zones irrigables et les cultures en sec, comme le blé et le tournesol dans les systèmes de cultures où ces productions non irriguées dominent.

Ces deux facteurs ont conduit, entre 2001 et 2007, à une baisse de la rentabilité de la culture de soja. Jusqu'en 2001, l'appui réglementaire a contribué à un maintien des surfaces françaises aux environs de 100000 ha. La réforme de la Pac, dite de l'Agenda 2000, a entraîné une perte de rentabilité des cultures oléagineuses dans l'assolement. Ainsi, le soja n'a plus bénéficié de l'aide spécifique irriguée pendant deux ans (2000 et 2001), contrairement au maïs. Le soja en sec comme en irrigué a cependant connu un pic de surfaces à cette période à la faveur de la mise en place de filières de soja de qualité et tracé. La très forte sécheresse et la canicule de 2003 ont marqué un coup d'arrêt dans le développement de la sole de soja en sec. En 2006 et en 2007, la mise en place du découplage des aides Pac a entraîné une perte de rentabilité des cultures irriguées en général, soja compris. L'augmentation soudaine du prix des graines en 2006 et en 2007 a favorisé, dans un premier temps, le maïs irrigué, car les prix des intrants azotés n'avaient pas encore «flambé » et parce que ce type de culture à fort rendement est davantage favorisé économiquement dans un contexte de prix élevé que des cultures à rendement moindre comme le soja.

Sur cette période, le soja destiné à l'alimentation humaine et produit contractuellement sur des volumes limités se comporte mieux en termes de rentabilité par rapport au soja pour I'alimentation animale (tableau 3).

Mais, à partir de mi-2008, le contexte très volatil des marchés des graines et des intrants a entraîné une inversion de tendance favorable à la rentabilité du soja. En effet, les prix des intrants ont fortement grimpé et ont favorisé le soja en augmentant le coût de production des cultures plus exigeantes comme le maïs. De plus, les marchés des graines ont de nouveau fortement baissé, retrouvant le niveau d'avant la flambée de 2006-2008 (Lecomte et al., 2009).

Ainsi, depuis 2006, la volatilité des prix entraîne la succession dans un temps réduit de scenarii extrêmes en termes de rentabilité relative des cultures. Mais, au-delà de ces fluctuations, des tendances lourdes se dégagent :

- I'augmentation du coût de l'énergie a un impact direct sur les charges opérationnelles des cultures (engrais, carburant, irrigation). S'agissant de la fertilisation azotée, le soja, en tant que légumineuse, est bien placé par rapport à d'autres cultures exigeantes en azote comme le maïs ;

- l'incertitude quant à l'évolution des marchés devrait raisonnablement conduire les agriculteurs à diversifier leur assolement et, ainsi, partager les risques économiques engendrés par cette volatilité des prix et des intrants ;

- sur le marché contractuel restreint, mais en augmentation, de I'alimentation humaine, la traçabilité est valorisée économiquement. Dans le contexte actuel de développement de 
Tableau 3. Évolution des écarts de marge brute du soja irrigué (débouchés alimentation animale et humaine) par rapport à différentes cultures concurrentes de 1999 à 2006.

\begin{tabular}{|c|c|c|c|c|c|}
\hline $\begin{array}{l}\text { Écart de marge brute }(€ / \text { ha) } \\
\text { du soja irrigué par rapport au' }\end{array}$ & Avant 2000 & $2000-2001$ & 2002 à 2005 & $\begin{array}{l}\text { Pac } 2006 \\
\text { (prix 2001-2005) }\end{array}$ & $\begin{array}{l}\text { Pac } 2006 \\
\text { (prix 2006) }\end{array}$ \\
\hline \multicolumn{6}{|c|}{ Soja alimentation animale } \\
\hline Maïs irrigué & 101 & -179 & -149 & -149 & -327 \\
\hline Tournesol en sec & 237 & 162 & 192 & 57 & 67 \\
\hline Blé tendre en sec & 385 & 115 & 145 & 10 & -53 \\
\hline Blé dur en sec & 48 & -153 & -123 & -88 & -195 \\
\hline \multicolumn{6}{|c|}{ Soja alimentation humaine } \\
\hline Maïs irrigué & 336 & 56 & 86 & 86 & -57 \\
\hline Tournesol en sec & 472 & 397 & 427 & 292 & 337 \\
\hline Blé tendre en sec & 620 & 350 & 380 & 245 & 217 \\
\hline Blé dur en sec & 282 & 82 & 112 & 147 & 73 \\
\hline
\end{tabular}

${ }^{1}$ L'écart de marges brutes affiché dans chaque case est égal à (marge brute du soja - marge brute de la culture concurrente). Ainsi, une valeur positive de cet écart est à l'avantage économique du soja. A contrario, une valeur négative est à l'avantage de la culture concurrente.

Tableau 4. Surfaces de soja prises en compte dans l'enquête Onidol-Cetiom au regard des surfaces totales implantées en France, données pour 2006 et 2008 (en hectares).

\begin{tabular}{|c|c|c|c|c|c|c|}
\hline \multirow[b]{2}{*}{$\begin{array}{l}\text { Zones de culture } \\
\text { du soja }\end{array}$} & \multicolumn{3}{|c|}{ Première enquête (mai 2007-février 2008) } & \multicolumn{3}{|c|}{ Deuxième enquête (novembre 2008-février 2009) } \\
\hline & $\begin{array}{l}\text { Surface de soja en } \\
\text { France en } 2006^{a}\end{array}$ & $\begin{array}{l}\text { Surface enquêtée } \\
2006^{\text {b }}\end{array}$ & $\begin{array}{l}\text { Taux des surfaces } \\
\text { françaises } \\
\text { enquêtées (\%) }\end{array}$ & $\begin{array}{l}\text { Surface de soja en } \\
\text { France en } 2008^{a}\end{array}$ & $\begin{array}{l}\text { Surface enquêtée } \\
\text { en } 2008^{\text {b }}\end{array}$ & $\begin{array}{l}\text { Taux des surfaces } \\
\text { françaises } \\
\text { enquêtées (\%) }\end{array}$ \\
\hline Sud-Ouest & 33700 & 24106 & 72 & 14800 & 13245 & 89 \\
\hline Est et assimilées & 12200 & 5063 & 42 & 7900 & 3560 & 45 \\
\hline Total & 45900 & 29169 & 64 & 22700 & 16805 & 74 \\
\hline
\end{tabular}

${ }^{a}$ Données du SCEES 2008 arrondies à la centaine supérieure.

${ }^{\text {b }}$ Surfaces déclarées par les opérateurs enquêtés.

débouchés tracés, conventionnels ou biologiques, une valorisation économique de cette traçabilité sur certaines filières de l'alimentation animale est tout à fait envisageable, ce qui n'était pas le cas il y a quelques années.

Au-delà de l'approche économique, les différents éléments du contexte actuel favorables à l'introduction du soja dans les assolements seront abordés dans la partie perspective.

\section{Collecte française de qualité pour des débouchés en graines entières}

Au niveau de la collecte de graines de soja, l'enquête menée par l'Onidol et le Cetiom a ciblé les principales coopératives et négociants des deux grandes zones de culture : le SudOuest et l'Est de la France (de Rhône-Alpes à I'Alsace). Une première série d'interviews a été réalisée auprès de 28 responsables des productions végétales ou directeurs de structures (23 dans le Sud-Ouest et cinq dans l'Est) entre mai 2007 et mars 2009. Une seconde série a été rajoutée de novembre 2008 à février 2009 pour recueillir l'analyse de 19 opérateurs (pour l'essentiel, communs avec la première série) après la chute drastique des surfaces enregistrées en France en 2008 (22 685 ha). La technique de l'entretien en face à face a été privilégiée. Les deux séries d'entretiens ont permis d'enquêter l'équivalent de 65 à $75 \%$ des surfaces françaises selon l'année considérée (tableau 4), conférant à l'étude une bonne représentativité malgré un léger déséquilibre en faveur de la zone Sud-Ouest (Labalette et al., 2009).

L'ensemble de la production française est issu de variétés conventionnelles sélectionnées, pour l'essentiel d'entre elles, par les deux semenciers français restants (RAGT Semences et EURALIS Semences). En effet, aucune variété génétiquement modifiée n'étant autorisée en culture ni dans I'UE ni, par conséquent en France, ces deux obtenteurs ont ciblé leurs efforts de sélection sur les besoins des marchés hexagonal et européen en exploitant des res- sources génétiques conventionnelles, contrairement aux semenciers engagés sur les marchés américains. La proportion de graines de soja bio produite en France s'avère élevée avec 10 à $12 \%$ de la collecte enquêtée (12\% de la collecte 2006 selon l'enquête 2007-2008 et $10 \%$ de la collecte 2008 selon l'enquête 2008-2009), chiffres en parfaite cohérence avec ceux de l'enquête postale Cetiom 2007. Héritage sans doute des procédures mises en place en 2000 et en 2001, une grande majorité du soja français reste tracée et de nombreux collecteurs (46\% en 2006) ont engagé une production contractuelle, à destination notamment de l'alimentation humaine (tableau 5).

En 2006, et contrairement aux résultats de la précédente étude Onidol-Cetiom de 2002, il n'y avait plus de graines françaises mises en marché pour la trituration (extraction de I'huile) en raison de l'irrégularité et de la faiblesse des volumes produits (arrêt de la trituration de soja français à l'usine de Sète en 2003). Cependant, plus de $70 \%$ des graines collectées étaient encore destinées à l'alimentation 
Tableau 5. Caractéristiques de la collecte de graines de soja 2006 enquêtée (Onidol-Cetiom 2007-2008).

\begin{tabular}{|ll|}
\hline Trait & $\begin{array}{l}\text { Collecte } \\
\mathbf{2 0 0 6}\end{array}$ \\
\hline $\begin{array}{l}\text { Part de la collecte bio dans le total } \\
\text { collecté }\end{array}$ & $12 \%$ \\
\hline $\begin{array}{l}\text { Nombre de collecteurs pratiquant } \\
\text { une production tracée }\end{array}$ & $60 \%$ \\
\hline $\begin{array}{l}\text { Nombre de collecteurs engagés } \\
\text { dans des contrats destinés à } \\
\text { I'alimentation humaine }\end{array}$ & $46 \%$ \\
\hline
\end{tabular}

animale et, plus précisément, à des unités traitant la graine entière par des procédés thermiques ou thermomécaniques (extrusion, expansion-toastage, toastage, etc.). Quant aux débouchés en alimentation humaine, ils ont au contraire sensiblement augmenté entre 2001 et 2006 en volume comme en proportion avec plus de $25 \%$ des tonnages collectés en 2006, contre $5 \%$ en 2001 (figure 5). Ainsi, l'enquête permet d'établir une ventilation des utilisations de la collecte française 2006 (123000 tonnes de graines) de 91000 tonnes pour l'alimentation animale et de 32000 tonnes pour le débouché en alimentation humaine.

Deux ans après, en 2008, cette répartition s'est trouvée bouleversée par la forte diminution des surfaces de soja. La collecte s'est alors révélée, pour la première fois de l'histoire de cette culture en France, orientée majoritairement vers I'alimentation humaine qui a vu ses volumes encore croître depuis 2006 suite à l'entrée de nouveaux organismes stockeurs sur ce marché attractif (figure 5). A contrario, la fai-

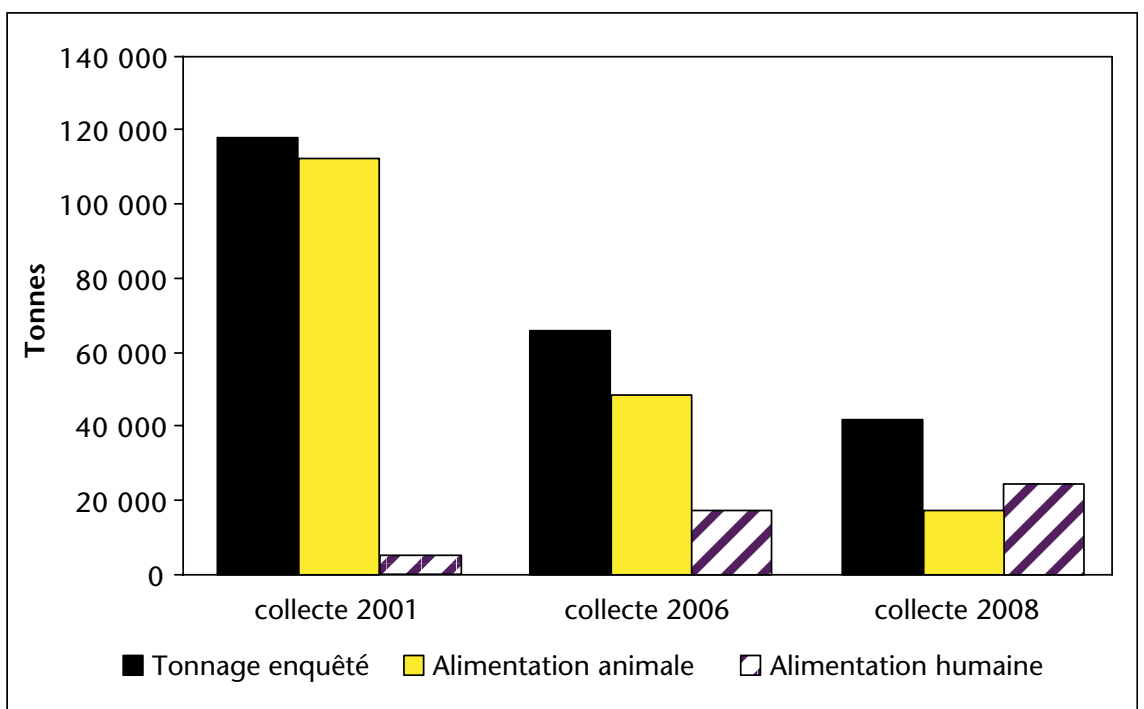

Figure 5. Évolution des débouchés des graines de soja chez les collecteurs enquêtés en France entre 2001 et 2008, enquêtes Onidol-Cetiom 2002; 2007-2008 et 2008-2009.

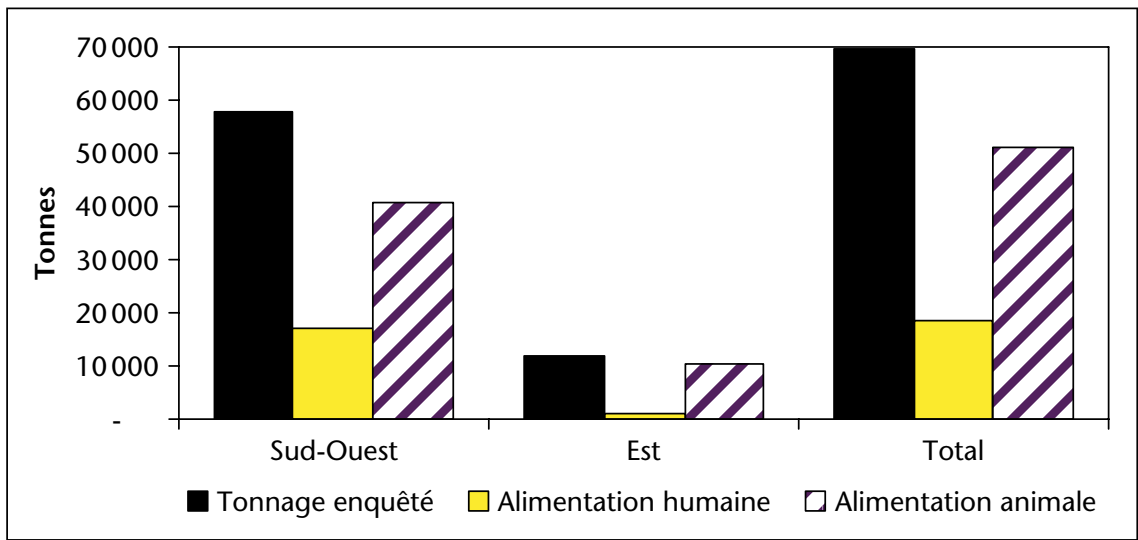

Figure 6. Répartition des débouchés des graines de soja chez les collecteurs enquêtés dans les deux principales zones de production en 2006, enquête Onidol-Cetiom 2007-2008. blesse des volumes destinés à l'alimentation animale est frappante cette année là, ce qui a contribué à fortement déstabiliser les utilisateurs traditionnels français de ce secteur.

Si I'on examine la répartition spatiale des débouchés, force est de constater que les graines collectées dans la zone Est sont principalement destinées à l'alimentation animale alors que les deux débouchés sont présents pour le Sud-Ouest. En effet, dans la zone Est, et notamment en Rhône-Alpes, en Franche-Comté et en Bourgogne, le soja a été historiquement développé dans un objectif d'autoconsommation par les élevages locaux. Des opérateurs régionaux ont alors investi dans des outils de traitement de la graine entière (extrusion), en pariant sur le gain logistique permis par une graine locale par rapport à un tourteau acheminé depuis la bordure maritime. En revanche, le Sud-Ouest, moins enclavé et plus gros producteur, a pu jouer sur tous les tableaux et s'ouvrir largement aux demandes provenant d'autres régions françaises, voire étrangères, pour le débouché en alimentation humaine (figure 6).

\section{Des exigences et des prix qui diffèrent selon les débouchés}

La production de soja destiné à l'alimentation humaine est en général contractualisée entre les organismes collecteurs et les agriculteurs et doit respecter un cahier des charges établi entre l'organisme collecteur et son client industriel. Comme décrit plus loin, I'humidité, la teneur en protéines, la quantification du caractère d'OGM, la propreté et l'état sanitaire des lots, ainsi que l'obligation d'une traçabilité élevée figurent systématiquement dans les cahiers de charges (tableau 6). Pour respecter ces cahiers de charges, les collecteurs sont parfois dans l'obligation de refuser des lots à la récolte et doivent engager des opérations de postrécolte dont le coût est relativement élevé (tableau 3).

Les graines de soja délivrées aux industriels du secteur animal doivent répondre aux normes de commercialisation en vigueur (14\% d'humidité et $2 \%$ d'impuretés au maximum). Dans certains cas, les industriels demandent qu'elles soient tracées et qu'une quantification de l'éventuelle présence d'OGM soit réalisée. Ils n'imposent, en revanche, pas de seuil de teneur minimale en protéines même s'ils disent attendre un contenu d'au moins $38 \%$ sur la matière sèche.

Les prix payés aux agriculteurs pendant la période étudiée varient fortement selon la fluctuation des cours mondiaux de la graine de soja, mais aussi selon son mode de production et son débouché. La flambée des cours des céréales de fin 2007 s'est traduite par une forte diminution des surfaces de soja et par 
Tableau 6. Critères retrouvés dans les cahiers des charges lies à l'approvisionnement en graines de soja pour I'industrie des soyfoods - Enquêtes Onidol-Cetiom 2007-2008 et 2008-2009.

\begin{tabular}{|c|c|c|}
\hline Critères & $\begin{array}{l}\text { Toujours présents dans le cahier } \\
\text { des charges }\end{array}$ & $\begin{array}{l}\text { Parfois présents dans } \\
\text { le cahier des charges }\end{array}$ \\
\hline Humidité & 14 ou $15 \%$ maximum & \\
\hline Teneur en protéines & $\begin{array}{l}40 \% \text { minimum sur la matière sèche } \\
\text { en général, } 47 \text { ou } 48 \% \text { maximum }\end{array}$ & \\
\hline Taux d'impuretés & $2 \%$ maximum & \\
\hline $\begin{array}{l}\text { Taux maximum ou absence totale } \\
\text { de graines vertes, graines noires, } \\
\text { graines cassées, demi-graines }\end{array}$ & Variable selon les opérateurs & \\
\hline $\begin{array}{l}\text { Traçabilité de la production et } \\
\text { de la chaîne d'approvisionnement }\end{array}$ & $\begin{array}{l}\text { Description des documents } \\
\text { et des contrôles exigés }\end{array}$ & \\
\hline Contenu en $\mathrm{ADN}$ transgénique & $\begin{array}{l}<0,01 \% \text { (opérateurs français } \\
\text { par exemple) ou }<0,1 \%\end{array}$ & \\
\hline Liste de variétés & & très souvent \\
\hline $\begin{array}{l}\text { Taille des graines (diamètre ou } \\
\text { via poids de } 1000 \text { graines) }\end{array}$ & & $\begin{array}{l}\text { Rare (et si oui, } \\
\text { préférence } \\
\text { pour de grosses graines) }\end{array}$ \\
\hline $\begin{array}{l}\text { Identification et/ou proportion de } \\
\text { chaque variété constituant le lot livré }\end{array}$ & & Parfois \\
\hline Couleur de la graine & & Rare \\
\hline $\begin{array}{l}\text { Obligation d'utilisation de semences } \\
\text { certifiées }\end{array}$ & & Très rare \\
\hline Teneur en isoflavones & Non & $\begin{array}{l}\text { Non, mais parfois } \\
\text { contrôlée }\end{array}$ \\
\hline
\end{tabular}

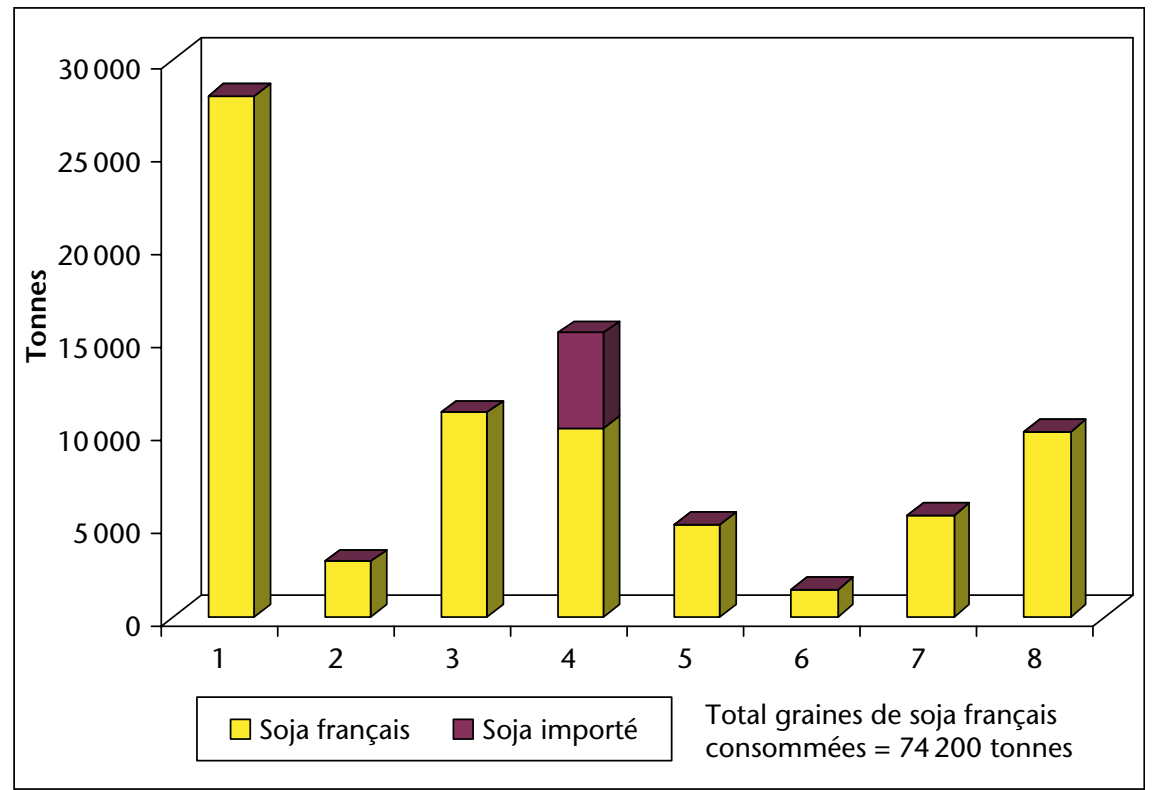

Figure 7. Sources d'approvisionnement des huit unités enquêtées de traitement de la graine entière de soja pour I'alimentation animale en 2006, enquête Onidol-Cetiom 2007-2008. un moindre intérêt des agriculteurs pour s'engager contractuellement. Pour stimuler l'offre, les industriels du secteur des soyfoods ont dû faire passer la prime accordée au soja destiné à l'alimentation humaine de $50 € / \mathrm{t}$ de graines avant la flambée des cours en 2006 (et même 30 à $40 €$ certaines années précédentes) à plus de $100 € / \mathrm{t}$ (tableau 7). Ce montant de $100 € / t$ correspond d'ailleurs peu ou prou aux surcoûts évalués par le Cetiom pour la production de soja pour l'alimentation humaine versus alimentation animale et il ne serait pas illogique de voir cette référence $s$ 'installer durablement. Le différentiel observé en 2008 entre origines bio et conventionnelle s'établit entre 100 et $130 € /$ tonne et plus. L'écart plus important encore pour le soja bio destiné à l'alimentation animale peut surprendre, mais il est à nuancer par les très faibles volumes en jeu pour ce débouché, la production bio étant quasiment toute absorbée par l'alimentation humaine et insuffisante par rapport à la demande.

\section{Utilisation en alimentation animale fragilisée}

Dans la mesure où plus aucune graine française non bio n'allait en trituration pour l'extraction de l'huile au moment de l'étude, seuls des industriels produisant de la graine entière transformée ont été interrogés.

Les huit opérateurs ainsi enquêtés ont traité 75000 tonnes de graines de soja en 2006. Ils sont localisés, soit près de leurs sources en soja dans les deux principales régions de culture, soit près de leurs clients éleveurs dans l'Ouest de la France. Les procédés qu'ils utilisent couplent le plus souvent effets mécanique et thermique (extrusion à $47 \%$ et toastageexpansion à $40 \%$ des tonnages de graines transformés) à même de baisser aux niveaux requis (10 UTI/mg) les FAT pour assurer la digestibilité de la graine. La graine extrudée ou toastée obtenue affiche une forte densité énergétique et protéique que finalement peu d'animaux valorisent correctement. De plus, elle est souvent confrontée, lors de la formulation des aliments, à la concurrence de l'association du tourteau de soja riche en protéines, à des matières premières riches en énergie et beaucoup moins coûteuses que l'huile (céréales, maïs) ou même à de l'huile moins coûteuse en général, comme celle de palme.

Les unités enquêtées partagent des traits communs : petite à moyenne taille des installations (entre 600 et 30000 tonnes de graines/an), obsolescence plus ou moins marquée des équipements, fonctionnement en sous-capacité (60\% de la capacité totale de 136000 t/an en 2006 et $36 \%$ en 2008), approvisionnement 
majoritairement en soja français (7\% de graines importées en 2006 et $30 \%$ en 2008) (figures 7,8 ). Ces unités achètent préférentiellement du soja français avant tout pour des questions de facilité d'organisation de l'approvisionnement (Labalette et al., 2009). Des entretiens il ressort que, dans bon nombre de cas, le caractère tracé du soja se valorise mal chez le client fabricant d'aliments, car les filières animales qui consomment le soja extrudé ne font pas, toutes, partie de productions avec cahier des charges comme le Label rouge (cas des dindes ou des jeunes animaux des filières tout venant par exemple).

Ainsi, construites pour la plupart dans les années 1990 en pleine expansion des surfaces de soja, les unités d'extrusion ou assimilées implantées sur le territoire français ont petit à petit fermé ou réduit leur capacité de production. Aujourd'hui vieillissantes, les unités restantes sont handicapées par une rentabilité économique fragile (forts coûts énergétiques et de maintenance des équipements, faible valorisation du soja extrudé, traçabilité peu ou pas rémunérée du soja français) et par la chute des surfaces qui réduit la disponibilité des graines à proximité. Pour autant, et la répartition des débouchés de la collecte française le démontre, le débouché de l'alimentation animale est essentiel à la fois pour assurer une sortie aux volumes non valorisables en alimentation humaine, mais aussi pour conserver des surfaces de soja significatives sur notre territoire et, ainsi, une dynamique dans la filière de production.

\section{Marché de I'alimentation humaine tourné vers les ressources locales}

Les graines françaises destinées à l'alimentation humaine étant valorisées dans le secteur des

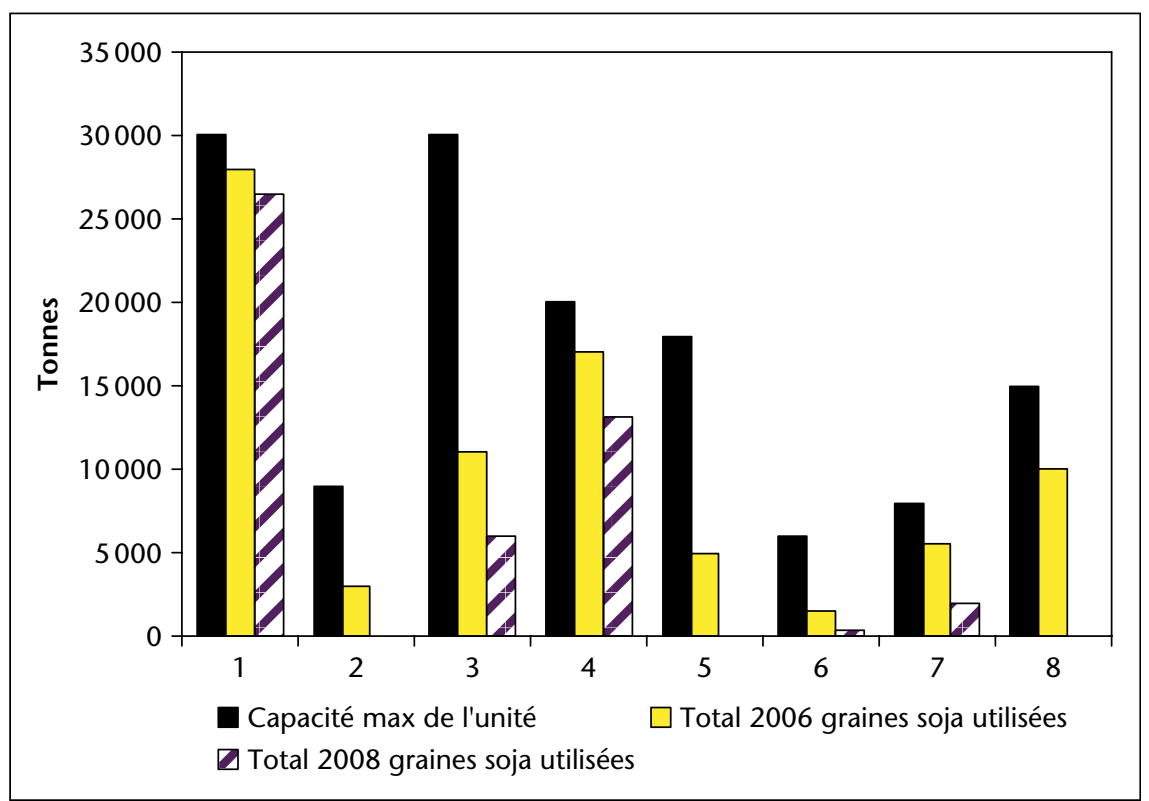

Figure 8. Niveaux d'utilisation des huit unités enquêtées de traitement de la graine entière de soja pour l'alimentation animale en 2006 et 2008, enquêtes Onidol-Cetiom 2007-2008 et 2008-2009. Pas de données collectées pour les unités 2, 5 et 8 en 2008-2009. soyfoods, I'enquête utilisateur a été concentrée sur ce domaine. Ainsi, au cours de l'étude, sept opérateurs ont été enquêtés : les quatre principaux fabricants français de soyfoods et trois étrangers (Belgique, Espagne, Italie).

Les industriels français déclarent avoir consommé, en 2006, environ 23000 tonnes de graines de soja français, ce qui apparaît tout à fait cohérent par rapport aux chiffres de l'enquête collecteurs pour la même année. Les trois étrangers ont eux, utilisé 38500 tonnes de graines françaises en 2006. Au total, l'étude aurait donc permis d'enquêter environ la moitié de la production européenne de soyfoods.

Les approvisionnements doivent, bien entendu, respecter des cahiers de charges relativement contraignants, que ce soit sur des aspects technologiques (teneur en protéines notamment), sanitaires ou de pureté (tableau 7). Les opérateurs agissent assez différemment pour ce qui concerne le critère variétal. La majorité établit une liste de variétés recommandées (ou de variétés non désirables) en concertation avec les fournisseurs de graines en prenant en compte leur richesse en protéines, mais aussi, pour certains d'entre eux, leurs caractéristiques organoleptiques, évaluées préalablement au cours de tests sensoriels après fabrication des produits en laboratoire ou à l'échelle pilote. D'autres critères, souvent évoqués lors de l'enquête 2002, comme la couleur de la graine ou du hile, ne sont plus ou peu mentionnés, probablement en raison du recours beaucoup plus systématique au dépelliculage en amont des procédés de transformation. Enfin, la teneur en isoflavones n'apparaît pas dans les cahiers de charges enquêtés probablement en raison de l'absence de méthodes $d^{\prime}$ analyses normalisées pour les doser et des débats observés, en particulier en France, sur leurs effets santé potentiels. Ces controverses se retrouvent dans l'attitude des industriels, les opérateurs français cherchant, semble-t-il, plutôt à limiter leur concentration dans les produits finis, tandis qu'en Espagne, la richesse en isoflavones des boissons au soja du plus gros fabricant est très visiblement mise en avant sur l'emballage.

Cependant, malgré ces quelques divergences, une tendance à la convergence des cahiers des

Tableau 7. Prix payés aux agriculteurs pour les graines de soja en 2006 et en 2008 dans les zones Sud-Ouest et Est (moyennes de prix communiqués par les organismes stockeurs pondérées par les surfaces relatives des deux zones), enquêtes Onidol-Cetiom 2007-2008 et 2008-2009 (en €/t).

\begin{tabular}{|c|c|c|c|c|}
\hline & \multicolumn{2}{|c|}{ Soja conventionnel } & \multicolumn{2}{|l|}{ Soja bio } \\
\hline & Récolte 2006 & Récolte $2008^{a}$ & Récolte 2008 ${ }^{a}$ & Prime bio en 2008 \\
\hline Alimentation animale & 211 & 338 & 476 & +138 \\
\hline Alimentation humaine & 258 & 448 & 547 & +98 \\
\hline Prime alimentation humaine & 47 & 111 & 71 & \\
\hline
\end{tabular}

a Prix provisoires communiqués en milieu de campagne 2008-2009. 
charges ressort et ce mouvement devrait se poursuivre, tout au moins entre les industriels français.

En termes d'approvisionnement, la part du soja bio pour le marché français des soyfoods s'établit en 2006 à $30 \%$, et la demande serait encore amenée à croître. Les graines utilisées en 2008, conventionnelles comme bio, sont désormais exclusivement d'origine française, tandis que, chez les industriels européens interrogés, un quart de l'approvisionnement annuel provient déjà de la production française (figure 9). Cette tendance à privilégier un approvisionnement local serait partagée par de plus en plus de fabricants européens de soyfoods (en Autriche ou en Italie, par exemple) au détriment des importations en provenance de pays tiers, pourtant considérées comme moins chères (Canada, Brésil, voire Chine pour le soja bio, etc.). Les opérateurs justifient cette évolution par des difficultés croissantes à s'assurer du caractère tracé des sojas en provenance de ces zones, mais aussi par la garantie offerte par des chaînes logistiques raccourcies en Europe et par la prise de conscience généralisée des consommateurs sur des questions environnementales, comme la déforestation assimilée à l'origine brésilienne pour le soja (Labalette et al., 2009). Les industriels rencontrés établissent en général des contrats annuels avec leurs fournisseurs, organismes collecteurs ou plus rarement agriculteurs. Les engagements portent sur des superficies ou des volumes délivrés, des périodes de livraison et le respect d'un cahier de charges. Une prime pour les teneurs en protéines supérieures à 40 ou $41 \%$ de la matière sèche est souvent versée et cette politique, pratiquée largement par les opérateurs français et par de plus en plus de fabricants européens, aurait, selon leurs propres dires, significative- ment contribué à améliorer la qualité des lots fournis au cours des dernières années. Les prix sont fixés avant ou au moment de la plantation, mais parfois aussi après selon des modalités variant entre opérateurs et entre années, ce qui a rendu difficiles les opérations de contractualisation dans un passé récent marqué par la forte baisse des superficies en soja. C'est pourquoi les collecteurs de graines et les fabricants de soyfoods français se sont concertés en 2009, sous l'égide de l'interprofession des oléagineux, pour établir des recommandations sur lesquelles les opérateurs privés pourront s'appuyer lors de la rédaction de leurs accords de contractualisation. L'objectif est de sécuriser les approvisionnements et de favoriser le meilleur partage possible des risques et de la valeur ajoutée. On y trouve, en particulier, les points suivants: détermination d'un prix objectif prenant en compte un rapport de prix avec le maïs, considéré comme la principale culture de comparaison dans la rotation; fixation de prix minimum et maximum, application d'un cahier de charges et engagement sur trois ans des opérateurs. En 2010, plusieurs collecteurs ont mis en place des contrats pour le soja d'alimentation humaine intégrant ces principes.

Le même type de démarche s'avèrera sans doute rapidement nécessaire pour faciliter la contractualisation avec le secteur de l'alimentation animale, et notamment dans le cas de filières locales intégrées.

\section{Et l'avenir ? \\ Un regain d'intérêt du soja dans les rotations}

D'un point de vue technique, des progrès significatifs peuvent être envisagés à court terme sur les deux freins majeurs de la production

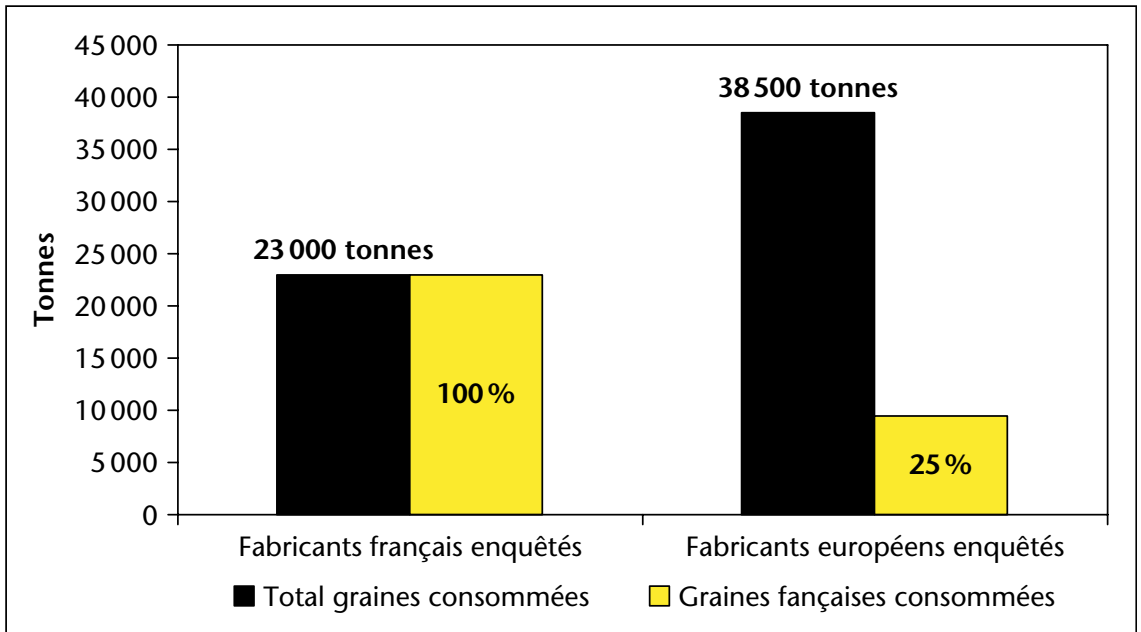

Figure 9. Sources d'approvisionnement en soja des fabricants de soyfoods en 2008. Enquête Onidol-Cetiom 2008-2009 (Onidol, 2009). (désherbage et irrigation), améliorant ainsi la compétitivité économique de cette culture.

En effet, l'arrivée récente sur le marché (campagne 2010) du nouvel herbicide de postlevée (Pulsar 40), à spectre large (antigraminées et antidicotylédones) contribuera certainement à la meilleure maîtrise d'adventices difficiles à contrôler (datura, xanthium, ambroisie à feuilles d'armoise, morelle, etc.). L'adoption sur 15 à 20000 ha de cet herbicide dès 2010, avec un bon niveau de satisfaction des producteurs, est un signe qui le montre clairement. Cette innovation, qui apporte des quantités de matière active faibles à l'hectare, est de plus tout à fait compatible avec les moyens de lutte mécanique, binage en particulier, et s'inscrit bien dans le cadre d'une utilisation restreinte $d^{\prime}$ intrants chimiques sur cette culture. Elle devra cependant $s^{\prime}$ utiliser de manière raisonnée au sein de la rotation, car la matière active employée appartient à une famille (inhibiteurs d'ALS) déjà largement employée en grandes cultures et pouvant ainsi entraîner des risques $d^{\prime}$ apparition de résistances de mauvaises herbes si des précautions d'alternance de matières actives dans la rotation ne sont pas prises.

En matière $d^{\prime}$ irrigation, la mise en ligne depuis 2008 sur le site du Cetiom de l'outil de pilotage de l'irrigation « Irrisoja » devrait permettre aux producteurs et aux conseillers qui les encadrent (conseils irrigations des chambres d'agriculture, etc.) une optimisation améliorée des apports. En complément, des travaux ont été initiés en 2010 dans le cadre du GIE des sélectionneurs de soja, soutenu par l'Onidol et le Cetiom, sur l'étude de semis très précoces dans le but de réduire, en décalant le cycle de la culture, les quantités d'eau apportées tout en maintenant un niveau de productivité et de qualité satisfaisant.

De plus, en raison de ses qualités environnementales, la culture de soja pourrait bénéficier de la mise en place de mesures réglementaires, soit obligatoires, soit incitatives. La révision en cours des autorisations de prélèvements d'eau, en application de la loi sur l'eau et les milieux aquatiques (Lema), pourrait favoriser le soja à la place d'une partie des cultures de maïs, en raison de ses besoins en eau inférieurs. Le possible développement géographique de la chrysomèle sur maïs, actuellement localisée dans quelques secteurs de l'Est de la France, pourrait offrir de nouvelles possibilités de culture du soja en raison de la mise en place de zones de protection obligatoires. Le quatrième programme en cours de la directive nitrates oblige, dans les zones vulnérables, la couverture automnale des sols. Dans ce cadre, la production de soja en dérobé, après une orge par exemple, serait une opportunité pour combiner couverture des sols et production de graines : les expérimentations récentes menées par le Cetiom 
ont confirmé que cette technique permettait d'obtenir de bons résultats économiques... à condition de bien respecter quelques règles de base, spécifiques à ce mode de culture (Labalette et al., 2008).

De plus, des mesures agroenvironnementales nationales territorialisées (existant aujourd'hui ou en cours d'élaboration) incitant à la diminution de la quantité d'eau prélevée, à la réduction des quantités d'azote épandues ou à la diversification des cultures pourraient aider cette production à se relancer.

Enfin, la très bonne adaptation du soja à l'agriculture biologique, la volonté affichée par le Gouvernement de développer ce mode de production et l'évolution de la réglementation concernant l'incorporation des aliments en élevage bio vont certainement provoquer une augmentation des surfaces de soja bio: les prévisions de surfaces de soja bio pour 2011 (un doublement est annoncé) reflètent déjà cette évolution.

À ces facteurs agroenvironnementaux et aux dispositifs d'aides éventuellement associés, des éléments économiques encourageants devraient se rajouter et encourager la mise en place de cultures de soja bio, comme conventionnelles dans les exploitations françaises. D'une part, l'augmentation du coût de l'énergie est une tendance lourde et ce contexte favorisera les légumineuses comme le soja, car elles ne nécessitent pas d'engrais azoté de synthèse. D'autre part, la demande croissante en protéines tracées locales devrait inciter les opérateurs à se placer de plus en plus dans un cadre contractuel offrant, dans une approche pluri-annuelle, une sécurité de rémunération et une visibilité bénéfiques à tous.

\section{Et I'avenir? \\ Une hausse de la demande en soja local pour des filières de I'alimentation humaine mais aussi animale}

En effet, aux atouts de durabilité indéniables à l'échelle de la culture, se combinent aujour$d^{\prime}$ hui des signaux de marché favorables à la production de soja en France. Du côté des soyfoods, les fabricants reconnaissent que le marché a connu une croissance à deux chiffres (environ 15 \%) jusqu'en 2008. Malgré le ralentissement inhérent à la crise, on peut s'attendre à une reprise de la croissance de ce marché pour des raisons nutritionnelles renforcées à terme par une diminution de la consommation de protéines animales. Ainsi, avec une hypothèse de croissance de $10 \%$ par an sur la période 2010-2020, et pour un marché potentiel de graines revu à la baisse pour 2010 (70 à 80000 tonnes de soja par an selon nos derniers recoupements), le marché européen pourrait atteindre plus de 200000 tonnes de graines dans dix ans (environ 80000 ha) (figure 10). Les contraintes environnementales et de traçabilité devraient inexorablement pousser les industriels européens à se fournir dans I'UE. Les producteurs français qui bénéficient d'une avance avérée en matière de traçabilité et de respect des cahiers des charges pourraient relever le défi de couvrir $50 \%$ de cette demande, soit plus de 100000 tonnes par an (équivalent de 40000 ha environ) contre 30 à 35000 tonnes aujourd'hui, à condition d'organiser au mieux leur offre sans occulter la concurrence probable des pays de l'Est. En complément de ce débouché limité en volumes et exigeant, la valorisation en alimentation animale est incontournable pour accompagner un redéploiement des surfaces souhaité et souhaitable.
La valorisation en graines entières « extrudées » semble marquer le pas et offre, aujour$d^{\prime}$ hui, peu de perspectives de croissance pour des raisons décrites plus haut, d'où la stabilité retenue pour ce marché (50 000 t/an) lors de la tentative de projection à dix ans des débouchés de la graine de soja français (figure 11). L'utilisation en graines entières crues serait, elle, potentiellement intéressante, notamment dans le cadre de l'alimentation des porcs dans le Sud de la France, mais elle se heurte à la teneur trop élevée des graines en FAT malgré le progrès apporté par certaines variétés (20 à $25 \mathrm{UTI} / \mathrm{mg}$ ). Des solutions techniques peuvent être recherchées et on peut imaginer que ce débouché gagne un peu de terrain dans le futur, estimé prudemment à 25000 t/an à un horizon de dix ans (figure 11). Quant à la demande en tourteaux tracés de qualité, elle

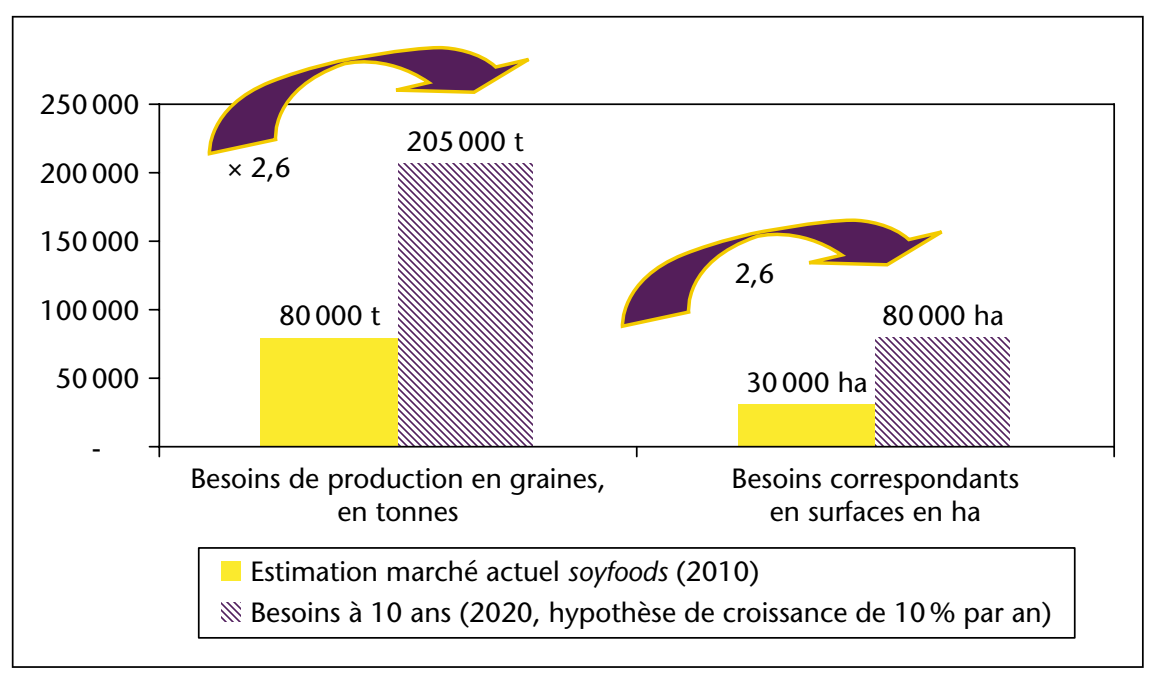

Figure 10. Hypothèses de croissance à dix ans des débouchés du soja dans l'industrie du soyfood en Europe (données ajustées en 2010).

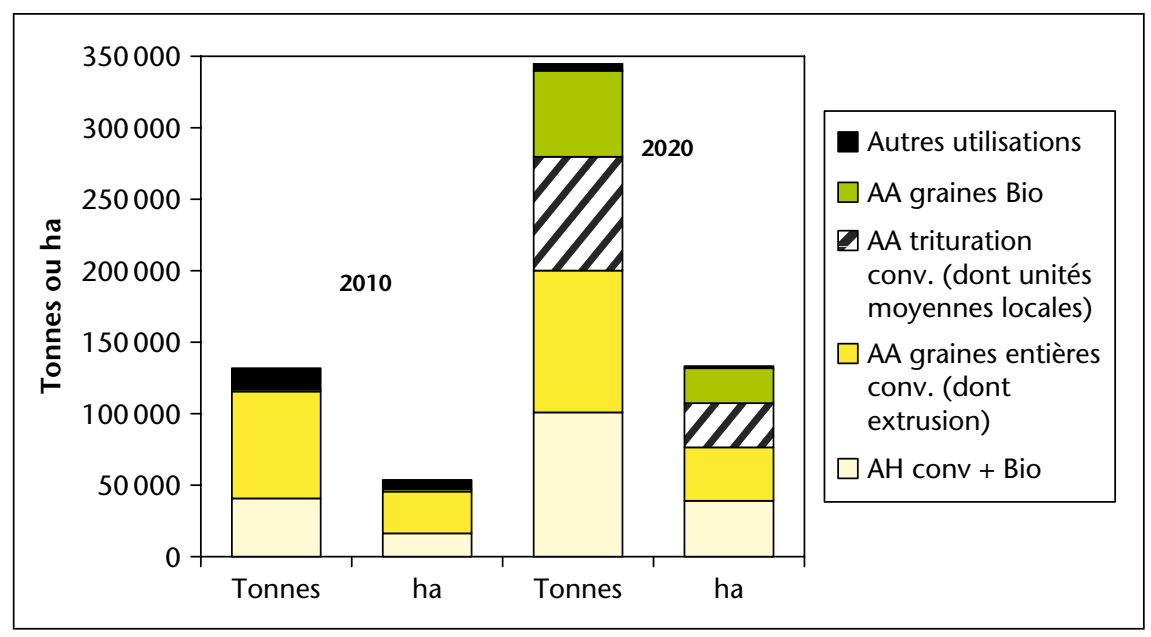

Figure 11. Tentative de projection à dix ans des débouchés de la collecte française de graines de soja, Conv: graines conventionnelles. $A A$ : alimentation animale; $A H$ : alimentation humaine. 
devrait être amenée à croître dans des bassins où existent à la fois une tradition de production de soja et des filières animales sous signe de qualité, désireuses de renforcer l'origine locale de leurs aliments. La même problématique affecte les filières animales bio qui seraient déjà aujourd'hui demandeuses d'un équivalent de plus de 30000 tonnes de graines de soja par an (selon des opérateurs bio). En effet, ces filières ne peuvent recourir à des tourteaux issus d'extraction à l'hexane et doivent utiliser exclusivement des matières premières produites à partir de cultures non OGM. À partir de janvier 2012, elles devront s'assurer du caractère bio de la totalité des matières premières utilisées (tolérance d'une proportion de $5 \%$ non bio aujourd'hui pour les monogastriques). Cette évolution ouvre donc des perspectives de croissance pour les graines de soja bio produites en France que l'on a estimé pouvoir doubler d'ici dix ans (figure 11). Les volumes qui pourraient être engagés dans de telles filières de valorisation locale bio ou conventionnelle restent cependant modestes au regard des capacités des unités de trituration classiques produisant plusieurs centaines de tonnes par jour. Des unités de transformations doivent donc être adaptées à cette contrainte tout en étant capables de valoriser les composantes de la graine mieux que ne le faisaient les usines d'extrusion en fournissant, d'une part, des tourteaux de qualité sans FAT et, d'autre part, de l'huile dont la vente contribuera à la rentabilité de l'activité. Le procédé d'extrusion-pression, déjà appliqué au soja aux États-Unis dans de nombreuses petites unités à « identité préservée » et utilisé en France pour la filière bio, répond à ces exigences, mais il a l'inconvénient de ne traiter que le soja, ce qui peut être pénalisant pour les investisseurs. Une autre option envisagée est le procédé de cuisson-pression déjà appliqué sur colza et tournesol dans de petites et moyennes unités industrielles en France, mais il reste nécessaire d'adapter les conditions opératoires au soja pour une désactivation efficace des FAT, le maintien de la digestibilité des protéines et un bon rendement d'extraction de l'huile. C'est l'objet de travaux engagés conjointement par le Cetiom et l'Onidol en cette fin 2010 sous l'impulsion d'acteurs économiques intéressés de la zone Centre-Est de la France. Une fois les procédés au point, la mise en œuvre d'une unité de trituration de taille moyenne (environ 25000 t/an) dans chacun des deux bassins pour valoriser les graines conventionnelles semble un objectif réaliste, soit un débouché supplémentaire à horizon de dix ans, d'environ 50000 t/an. Ce même procédé pourrait bien sûr être utilisé pour produire du tourteau bio à partir des graines de soja bio.

\section{Conclusion}

Au total, la reconquête d'une surface de 100 à 150000 ha de soja en France dans les cinq à dix ans à venir paraît un objectif compatible à la fois du point de vue agronomique (ces surfaces ont déjà été atteintes par le passé), économique et de marché (figure 11). Les deux débouchés, alimentation humaine et animale, devront faire l'objet d'un développement parallèle et le plus harmonieux possible en s'appuyant sur les avantages d'une graine locale et tracée permettant de sécuriser et d'améliorer le bilan environnemental des approvisionnements en graines, ainsi que sur les perspectives de croissance de la demande bio en France. L'ensemble de la filière devra, pour ce faire, rester mobilisé et renforcer son organisation aux échelons nationaux et régionaux. Elle pourra compter sur des opérateurs investis depuis longtemps sur le soja, que ce soit les deux semenciers français, les producteurs des grands bassins de cultures, les organismes collecteurs et les utilisateurs désireux de mieux valoriser les graines locales et, bien entendu, les organisations professionnelles, Onidol et Cetiom, pour lesquelles le soja doit renforcer sa place au sein de l'offre oléagineuse française.

Remerciements. Ces travaux ont bénéficié du soutien de l'ONIGC en 2007 et en 2008.

\section{RÉFÉRENCES}

AFZ et Cereopa, 2010. Base de données Feedbase (www.feedbase.com)

Daydé J, Labalette F, Chibarie JC. Current situation and future trends of the soybean production and market in Europe. In: Proceedings of the World Soybean Research Conference VIII, August 9-16, 2009, Beijing, China, www.wsrc2009.cn

Labalette $F$, Lecomte $V$. Le soja français, une filière dynamique. Oléoscope $2003 ; 71$ : 9-18.

Labalette F, Jouffret P, Lecomte V, Quinsac A. Le soja français, une culture bénéfique pour l'environnement au service de filières de qualité. Perspect Agric 2008 ; $346: 22-5$.

Labalette F, Bourrel C, Jouffret P, Lecomte V, Quinsac A, Ledoux S. Specificity and features of the soybean production in France. In: Proceedings of the World Soybean Research Conference VIII, August 9-16, 2009, Beijing, China, www.wsrc2009.cn.

Lacroix B, Desvignes P, Capdeboscq JB. Fertilisation azotée du soja après maïs. Oléoscope, 45 , mai-juin 1998.

Lecomte V, Jouffret P, Labalette F, Gagne R. Technical and environmental advantage of the soybean cultivation in France. In: Proceedings of the World Soybean Research Conference VIII, August 9-16, 2009, Beijing, China, www.wsrc2009.cn.

Onidol. L'avenir de la filière du soja français. Paris : Ed. Onidol, 2009.

Reau R, Jouffret P, Estragnat A, Cristante P. Pertes de nitrates dans les systèmes irrigués maïs-soja. Oléoscope, 45, mai-juin 1998. 